\title{
Epistemological Approaches to Dialogic Teaching in a Conventional Setting - Critical Review
}

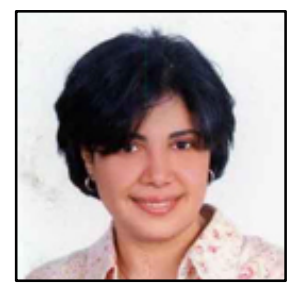

Nermine Abd Elkader

School of Education, University of Delaware

\begin{abstract}
Book review for Dialogic Pedagogy Journal: This is a review of the book 'Inspiring dialogue: Talking to learn in the English classroom' by Juzwik et al. (2013), New York, NY: Teachers College Press, 162 pages, \$ 32 (paper). The review looks critically at the theoretical framework of the book and compares it to the ontological tradition of Baktinian dialogue. The review aims to find the strengths of the book and meanwhile exposes its weaknesses in light of the interpretation of the Bakhtin's circle and modern Bakhtinian scholars of dialogic pedagogy.
\end{abstract}

Inspiring dialogue: Talking to learn in the English classroom is a book that tries to find solutions for some of the most expressed problems that teachers face with class dialogue within a discussionbased method of instruction. Chapter 1 gives the rationale for using dialogue in teaching but also maintains that dialogue could be a problem because both teachers and students have not learned to dialogue throughout their schooling experience (p.9). This is why the authors dedicate Chapter 2 to describe how teachers can develop a dialogic stance to help their students learn to talk and also to stimulate them to talk to learn. Developing a dialogic stance, according to the authors, entails that both teachers and students show a commitment to listening to one another and to responding to the speaker's argument rather than talking over it. In this sense, developing a dialogic stance implicates an ontological change in the teacher-student relationship that would allow the students to see and believe that their voices are valued and heard (p.31). For an ontological change to take place, the authors emphasize heavily the importance of reflection and meta-thinking for both teachers and students. Chapter 3 delineates one of these meta-thinking tools represented in a diagnostic survey that calls teachers to assess their attitude toward class discussion and reflect upon their practices that might be hindering the dialogue before they start planning for the dialogue. Chapter 4 points out meta-lessons in which teachers encourage students to think about what makes a good discussion as an opportunity for teachers to lay out the ground rules for discussion and to prevent bullying and disrespect among students during dialogue. Developing a dialogic stance, according to the authors, also means emphasizing the linguistic diversity in the dialogic classroom as a necessity for the students to use language to develop and share their thoughts and for teachers to develop the attitude of regarding students' home languages as a resource for learning rather than as a deficit for their English language skills. I find it valuable that in both Chapters 3 and 4, the authors give entry level teachers some clear distinctions between listening and responding authentically to students' participation and following an I-R-E (initiation, response, and 


\section{Epistemological Approaches to Dialogic Teaching in a Conventional Setting}

Nermine Abd Elkader

evaluation) pattern which is monologic ${ }^{1}$ teaching under the disguise of a pseudo discussion (Chinn, Anderson, \& Waggoner, 2001).

Another valuable dialogic practice that the book promotes is using dialogic provocations to encourage dialogue and enhance its persistence. The authors call the provocations "dialogic tools" (p.31) and claim that they can be provided by either the teachers or the students. For example, although the authors show that teachers might prefer teacher-led ones (at least one of them did), the authors insist that these tools -even the ones that are concerned with discussing the dialogue rules - can be prepared and led by the students. The authors, thus in Chapter 3, have a long list of dialogic provocations that can be prepared by the teachers and those that can be prepared by the students and suggest that students respond better to the class dialogue when they work with these tools. In Chapter 4, the authors introduce a method by which teachers can ensure to plan for dialogue for the whole academic year. The authors' initial purpose for planning for the long haul is to prevent teachers from growing weary of the dialogue on the long term (p.54) or to give up on it if they were met with one bad or flat session. Planning for the long haul, according to the authors, also allows teachers to stay focused on the state recommended curriculum and to meet the learning objectives as set by the CCSS (p.55). One of the most important concepts that Chapter 4 emphasizes, in my opinion, is the issue of assessment. The authors recommend formative assessment and once more emphasize the importance of dialogic tools in providing a means for rigorously assessing classroom participation away from any presumptions that in dialogue anything goes. The authors offer a rubric for assessing Socratic Seminar participation on p.66 that takes into account students who might be shy or might not wish to talk within the classroom context by looking at how the students have prepared for the discussion at home and how deep the questions, comments, and concerns they wrote in reflection about the material are. Thus, in assessing the students, the authors are careful to be sensitive to students' different personalities and the potential that some might be uncomfortable to speak in public.

Chapter 5 focuses on taking a dialogic stance in argumentative writing. I commend this chapter for moving away from the highly structured lesson planning that characterized the previous chapters to a more dialogic approach in writing arguments based on polyphony and multivocality (DePalma, 2010b; Sullivan, 2011). The authors in this chapter denounce the formalist approach of a five paragraph argumentative essay and stress the importance of teaching argumentative writing against a background of the social role that arguments play in actual life. Even though the authors provide templates of transition phrases and words that teachers should introduce to the students to help them understand how to enter an argument or transition among the different voices of an argument in their writing, the authors warn against using these words and phrases as a formulaic instead of understanding them as being generative rather than comprehensive. Moreover, in this chapter, the authors skilfully demonstrate how authentic dialogic conversations as represented in students' voices in a free classroom conversation or in talk shows can be transferred in writing an argument in such a way that allows the students to see arguments as a part of their normal everyday lived experience. In my view, this chapter is one of the strongest chapters in the book even in its empirical evidence as the students' voices in this chapter are authentic and indicative of an ontological participation in the discussion.

The last two chapters in the book emphasize using dialogic inquiry to promote better dialogic practices. In these chapters, the authors return to a metaphor that they have introduced in Chapter 1 in the book of a dialogic lesson being a draft rather than a final product. Thus the authors encourage and

\footnotetext{
${ }^{1}$ In monologic teaching, the teacher is the sole holder of knowledge which she wishes to transmit to the students and thus students' answers to teachers' questions need to align with the curricular goals and the lesson plan objectives that are foreknown by the teacher (Matusov, 2009)
} 


\section{Epistemological Approaches to Dialogic Teaching in a Conventional Setting}

Nermine Abd Elkader

demonstrate methods of discourse analysis and peer feedback to help teachers revise their practices based on the findings of their investigation. Both chapters are powerful in that they promote the concepts of reflective practitioners (Dewey, 1933) and community of practice (Lave \& Wenger, 1998) for learning and education. It is also worthy to note that the authors were realistic in guiding teachers to receive feedback from colleagues by alerting them to the importance of choosing people they trust and collaborate well with for their peer feedback group and in being prepared for the meeting by collecting the tools they used and excerpts of videos they recorded for their class sessions. The last section in the book draws the attention to the many challenges that can arise during a dialogic class and the authors' answers to these challenges. I find this last section in the book powerful as well since the authors delineate some of the challenges that emerged during their study and that are also well documented in the literature of class discussion especially in a culturally diverse classroom (Chinn et al., 2001; Solorzano, 1997; Wortham, 1995). The strength of exposing these challenges and how teachers dealt with them relies on the fact the authors' voice almost disappear and more space is given to teachers' voices as they reflect on their own practices and mistakes as they see them.

The authors use the appendices to talk in more detail about their research participants, the curriculum, and their research methodology. I have concerns about revealing to the reader that the study was a design or an intervention study only at the end of the book and in the appendix. This could create confusion throughout the book about whether the authors are describing successful dialogic practices or whether they are describing a dialogic philosophy as they see how it should be implemented in the classroom. Also, in the summary of findings, we hear the authors saying that students' participation flourished more when the teacher controlled the dialogue through prepared dialogic tools rather than letting the dialogue be planned and led by the students. I did not find evidence for this proclamation throughout the book except in one teacher's proclamation that her students struggled with student-led discussion. More evidence is needed on this important and unlikely point for it to be more empirical.

I commend reading Inspiring Dialogue to all teachers who are falling under the burden and pressure of Curriculum State Standards and want to create some life in their classrooms. The book explicitly maintains that the dialogic approach that the authors promote meets many of the standards for listening, speaking, and writing as outlined by the Common Core State Standard. The book also offers a contribution to the literature of discussion-based instruction in conventional classroom by showing how teachers can be prepared, trained, and guided through the process of implementing dialogue in their teaching. This is especially important when we talk about the teaching of English owing to the inherent connection between dialogue and language with language acquisition relying mainly on interaction (DePalma, 2010a). The book also finds some solutions for some of the issues that have been raised in the literature of class discussion mainly teacher's domination of the discussion (Chinn et al., 2001), lack of preparation on the students' part (Billings \& Fitzgerald, 2002), and digression and focus on personal issues rather than the learning material (Wortham, 1995). In this sense, I consider this book a manual for teachers and pre-service teachers who wish to implement a discussion based method of teaching in their classroom and to be able to measure, assess, and document students' success against the State standards.

However, there are many other issues and problems with the dialogic approach that the authors followed that the book does not tackle and does not seem to take into consideration. It seems that the authors, in this book, have followed an epistemological rather than an ontological approach to dialogue. Epistemological approaches focus on the dialogue as a medium through which legitimate knowledge that is known, defined, pre- contested, and finalized by the authoritative word is presented to the students (Matusov, 2011). Although the students' role in reflecting on and critically considering this knowledge is 
not diminished, it is still expected that students will reach an answer that has already been proven by another and that is considered to be a universal truth (Fishman, 1985). It is true that the authors commended this epistemological approach in order to orient the students toward dialogue knowing that few students have encountered dialogue throughout their schooling trajectory and thus do not always know how to dialogue (p.6). However, I still find it problematic that the authors recommend teachers to be in ultimate control of the dialogue including planning for the long haul. The authors went as far as comparing planning for the dialogue to preparing a good meal that needs to be well seasoned and marinated before served to the students. This conceptualization of dialogue contradicts how several Bakhtinian scholars defined dialogue, according to Bakhtin, as a human activity that is hard to be predicted, controlled, or submitted to the demands of any policy (Gardiner, 2002; Sidorkin, 1999). Such dialogue engages the students ontologically because dialogue is not a medium for education; rather dialogue is the education i.e. the ultimate end goal for the dialogue is dialogicity which Bakhtinian scholars define as the realization of the value of other consciousnesses in one's own understanding of any idea (Matusov, 2009; Sidorkin, 1999). In fact, Bakhtin's concept of carnival is where the most processes of rejuvenation, death, and re-birth including that of language development or rather mutation takes place away from the eyes of officialdom to the extent that participants sometimes have to hide behind costumes, masks, and farces (Gardiner, 2002). Ontological dialogue engages the students not because it is an interesting instructional method that makes learning more fun and less boring -although it certainly does - but because ontological dialogue is the essence of human existence and thus an educational project that follows this approach permeates the very essence of the students' existence.

Recently, the Dialogic Pedagogy community has witnessed a debate between Matusov and Wegerif (2014) about the ontological and epistemological nature of dialogic education. The debate was interesting at many levels but in my opinion, it highlights an important dilemma that dialogic educators are already starting to face as they try to find a place for ontological dialogue in the context of conventional education with its current status of seeking quantifiable and measureable one-size fits all standard for assessing students' learning. I believe one of the most important points of difference between Matusov and Wegerif in such a debate is the role of monologism in dialogic education. Wegerif believes that monologism is important at a large scale in dialogic teaching especially if we are seeking to present the students with well-established universal truths that are proved by hard evidence as in the fields of science and math. On the other hand, Matusov maintains that an ontological view of dialogic education cannot start out with an expectation of curricular endpoints and predictable and expected learning outcomes. The debate represents a gap between how the Bakhtin circle (Gardiner, 2002) and many other modern scholars (for example: Matusov, Sidorkin, Skidmore, and others) interpret dialogue as a natural human activity that is ongoing, open-ended, and intertwining with all aspects of human existence (Sidorkin, 1999) and how many other Western scholars (for example: Alvermann \& Hayes, 1989; Applebee, Langer, Nystrand, \& Garmoran, 2003) interpret dialogue as an activity that can be coached, scaffolded, and used as an instrument of instruction. This gap has always been attempted to be bridged by scholars who try to find a place for Bakhtinian dialogue in conventional education (for example: Dysthe, 2011) but are faced with the dilemma of standard-based policy and quantified measures that use the students' head as a unit of analysis (DePalma, 2010b) and thus feel the need to follow conventional methods for an approach that does not recognize these methods and does not acknowledge them as legitimately dialogic.

I see the authors' negligence or confusion of ontological dialogue in this study as problematic despite the fact that epistemological approaches to dialogue can be argued to be a pleasant alternative to the traditional lecture approach and can promote analytical and critical thinking which are according to Vygotskian scholarship more conducive for learning and retention of knowledge (Vygotsky, 1987). However, the epistemological approach is problematic in this study because the authors do not wish to 


\section{Epistemological Approaches to Dialogic Teaching in a Conventional Setting}

Nermine Abd Elkader

attain through it merely better students' engagement, achievement, and/or performance goals or even merely to satisfy the demands of the Common Core State Standards. The authors claim that dialogic teaching has become a mandate in our day and age in order to present to the society democratic citizens able to discuss and debate the bigger societal issues within a political climate that has become polarized and void of civility and respect for the other diverse viewpoints. However, throughout the book, we see the authors focusing on the teacher as the absolute authority figure in the classroom even to the extent that teachers are advised to prepare, select, and sequence the dialogic tools that will provoke students into dialogue. It is true that the authors showed other student-led dialogue tools but it is obvious that both authors and teachers prefer teacher-led tools and teacher-led dialogues (p. 45, 136). There were moments in the book when the authors resorted to a more ontological orientation for the dialogue (which makes me think that the authors struggled with ${ }^{2}$ rather than completely ignored this specific orientation) especially when the authors focused more on the students' voices and how they responded to the dialogic approach in argumentative writing in Chapter 5 or even when they encouraged teachers to deliberately reflect on their practices through participating in dialogic inquiry with their community of practice. However, students' voices appeared only sporadically throughout the study and they were always overcome by the teacher's voice even reflecting on their own mistakes as opposed to listening to the students also evaluating and even critiquing the dialogic approach and the teacher. The very fact that the authors claim that students struggled in the student-led dialogue makes me wonder if an authentic dialogue was actually taking place. DePalma (2010a) claims that when dialogue is used merely as an instrument of instruction rather than an authentic project that seeks students' voices as a legitimate source of knowledge, students' performance plummets in comparison with more teacher-centered practices. Matusov (2009) maintains that an epistemological approach to dialogue can potentially be more harmful to dialogue than a monologic one since it throws students into confusion about what is expected of them and even fear of repercussion if what they shared in one context could be taken against them in another. Shor and Freire (1987) maintain that in the dialogic classroom, the success of the dialogic project is only measured through the diminishing role and the diminishing voice of the teacher and the growing control and authority that the students gain of the dialogue.

Besides, going back to the cooking metaphor that the authors used throughout the book, I can't help but wonder what if some students did not like the meal that was prepared for them. The issue of pedagogical violence aimed at students who do not comply with the instructional goals of the teacher has been raised in several studies that did not even use Bakhtinian dialogue for a theoretical framework (see for example: Candela, 1999). Moreover, in dialogue, there will always be students who do not want to participate for ontological reasons such as that the material is of sensitive and personal nature to them (Hill, 2009; Wortham, 1995) or because they prefer to work in isolation rather than join a community of learners (Brown \& Renshaw, 2006). How can teachers thus deal with these students in a class that is supposed to prepare citizens for democracy while meeting state mandated standards as well? Shouldn't democracy entail a freedom of even non-participation (Kukathas, 2003)? Should students be penalized by grades in this instance?

This is the dilemma that I faced when I read Juzwik et al. (2013)'s book Inspiring Dialogue: Talking to Learn In the English Classroom. On the one hand, I find that the book offers sound arguments for the need for dialogue in traditional schools and for the value of providing teachers with dialogic tools that help them plan for instruction and achieve curricular goals. On the other hand, I have concerns about

\footnotetext{
${ }^{2}$ It is expected for the ontological dialogue to create a problematic for educators especially when educators try to satisfy the demands of a policy while truly seeking to engage in a democratic dialogue. The question was raised at the beginning of the book when the authors maintain that teachers refrain from the dialogic approach either because of their fear of losing control over classroom management or because they don't think their students are cognitively ready for it
} 


\section{Epistemological Approaches to Dialogic Teaching in a Conventional Setting}

Nermine Abd Elkader

the authors' ignoring students' agency within this project or the need to prepare teachers to acknowledge and respect this agency. Although the authors try to find ways for teachers not to fear the dialogic approach but to master it in such a way to make it easy to implement, to assess, and to improve on, I think more investigation into students' responses to the approach and the challenges that long term practices can reveal is needed to see if issues of disengagement, lack of motivation, and pedagogical violence (teachers' penalizing the students for not complying to their preset goals) would emerge, which in my view is likely to happen in any educational project that does not center on students' agency and their subjectivity.

\section{References}

Adler, M.J. (1984). The Paideia Program: An Educational Syllabus. New York: Collier Macmillan.

Alvermann, D. E, \& Hayes, D. A. . (1989). Classroom discussion of content area reading assignments: An intervention study. Reading Research Quarterly, 24(3), 305-335. doi: 10.230717477772

Applebee, A. N., Langer, J.A., Nystrand, M., \& Garmoran, A. (2003). Discussion-based approaches to developing understanding: Classroom instruction and student performance in middle and high school English. American Educational Research, 40(3), 685-730.

Billings, L., \& Fitzgerald, J. (2002). Dialogic discussion and the Paideia seminar. American Educational Research Journal, 39(4), 907-941. doi: 10.3102/00028312039004905

Brown, R., \& Renshaw, P. (2006). Positioning students as actors and authors: A chronotopic analysis of collaborative learning activities. Mind, Culture, and Activity 13(3), 247 - 259.

Candela, A. (1999). Students' power in classroom discourse. Linguistic and Education, 10(2), 139-163.

Chinn, C.A., Anderson, R.C., \& Waggoner, M.A. (2001). Patterns of discourse in two kinds of literature discussion. Reading Research Quarterly, 36(4), 378 - 411.

DePalma, R. (2010a). Language use in the two-way classroom: Lessons from a Spanish-English Bilingual Kindergarten. Tonawanda, NY: Multilingual Matters

DePalma, R. (2010b). Toward a practice of polyphonic dialogue in multicultural teacher education. Curriculum Inquiry, 40(3), 436-453. doi: 10.1111/j.1467-873X.2010.00492.x

Dewey, J. (1933). How We Think. A restatement of the relation of reflective thinking to the educative process (Revised edition). Boston, MS: D.C. Heath.

Dysthe, O. (2011). Opportunity spaces for dialogic pedagogy in test -oriented schools: A case study of teaching and learning in high school. In E. J. White \& M. Peters (Eds.), Bakhtinian pedagogy: Opportunities and challenges for research, policy and practice in education across the globe (pp. 21-46). New York, NY: Peter Lang Publishers.

Fishman, E. M. (1985). Counteracting misconceptions about the Socratic Method. College Teaching 33(4), 185-188. Gardiner, M. (2002). The dialogics of critique: M.M. Bakhtin and the theory of ideology. New York, NY: Routledge.

Hill, M. (2009). Beats, Rhymes and Classroom Life. New York, NY: Teachers College, Columbia University

Juzwik, M., Borsheim-Black, C., Caughlan, S., \& Heintz, A. (2013). Inspiring dialogue: Talking to learn in the English classroom. New York, NY: Teachers College Press.

Kukathas, C. (2003). The liberal archipelago: A theory of diversity and freedom. New York, NY: Oxford University Press.

Lave, J., \& Wenger, E. (1998). Communities of Practice. Retrieved June, 9(2008).

Matusov, E. (2009). Journey into dialogic pedagogy. New York, NY: Nova Science Publishers.

Matusov, E. (2011). Irreconcilable differences in Vygotsky's and Bakhtin's approaches to the social and the individual: An educational perspective. Culture \& Psychology, 17(1), 99-119. doi: $10.1177 / 1354067 \times 10388840$

Matusov, E, \& Wegerif, R. (2014). Dialogue on 'Dialogic Education': Has Rupert gone over to 'the Dark Side'? Dialogic Pedagogy Journal, 2, 1-20. Retrieved from Dialogic Pedagogy: An International Online Journal website: http//:dpj.pitt.edu doi:10.5195/dpj.2014.78

Shor, I, \& Freire, P. (1987). What is the "dialogical method" of teaching? Journal of Education, 169(3), 11-31. 
Sidorkin, A. M. (1999). Beyond discourse: Education, the self, and dialogue. Albany, N.Y.: State University of New York Press.

Solorzano, D. (1997). Images and words that wound: Critical race theory, racial stereotyping, and teacher education. Teacher Education Quarterly, 24(3), 5-19.

Sullivan, P. (2011). Qualitative data analysis using a dialogical approach. Thousand Oaks, CA: SAGE.

Vygotsky, L.S. (1987). Thinking and speech. In R. Rieber \& A. Carton (Eds.), The collected work of L. Vygotsky. New York, NY: Plenum.

Wortham, S. (1995). The Microstructure of multiculturalism: Experiencing the great books. Paper presented at the The Annual Meeting of the American Educational Research Association, San Francisco, CA.

Reviewer's short bio: Nermine Abd Elkader earned a Ph.D. degree from the University of Delaware in the Sociocultural and Communal Approaches in Education with a special focus on dialogic pedagogy and multicultural education. Nermine's research interests center on the ontological orientation of Dialogic Pedagogy and the role it plays in students' learning, engagement, and transformative educational experiences.

\section{(c) $) \mathrm{EY}$}

Articles in this journal are licensed under a Creative Commons Attribution 3.0 United States License.

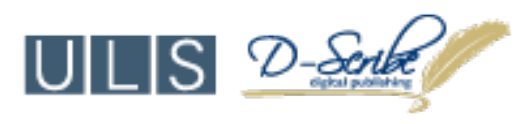

This journal is published by the University Library System, University of Pittsburgh as part of its D-Scribe Digital Publishing Program and is cosponsored by the University of Pittsburgh Press. 